\title{
Avaliação do Tratamento Não-Medicamentoso (Orientação Verbal) das Mastalgias Cíclicas
}

Autor: Flávio Nunes Sivini

Orientador: Prof. Dr. Cícero Ferreira Fernandes Costa

Dissertação apresentada ao Curso de Pós-graduação em Ginecologia e Obstetrícia, área de concentração em Tocoginecologia da Faculdade de Ciências Médicas da Universidade de Pernambuco, para obtenção do Título de Mestre em 23 de maio de 2000.

O objetivo deste estudo foi avaliar o tratamento nãomedicamentoso (Orientação Verbal) como primeira opção terapêutica para mulheres com mastalgia cíclica, e observar se fatores reprodutivos alteram os resultados. Conduzimos um estudo do tipo experimental nãocontrolado com uma amostra de 128 mulheres com uma história clara de mastalgia cíclica, tratadas com orientação verbal. Uma escala analógica visual da dor foi usada antes e após tratamento, a fim de avaliar a sua gravidade e classificamos as mastalgias em graus, I (leve), II (moderado) e III (severo), de acordo com a intensidade da dor. Usamos também o "Cardiff Breast Score" (CBS) modificado para avaliar a resposta clinica ao tratamento. Verificou-se um índice de sucesso de 59,4\% com a orientação verbal, mas não houve uma resposta com diferença estatisticamente significante entre os grupos $(p=0,16)$ com diferentes graus de mastalgia. O tempo de existência da dor e os fatores reprodutivos não influenciaram a resposta terapêutica, exceto, quando estudamos a influência da idade das pacientes. Pacientes com 40 anos ou mais foram mais beneficiadas com o tratamento não-medicamentoso e, nesse aspecto, houve diferença estatisticamente significante $\left(\chi^{2}=6,89 \mathrm{p}=0,01\right)$. O medo de que a dor mamária pudesse estar associada a um câncer oculto na mama esteve presente na maioria $(71,8 \%)$ dos casos na primeira consulta. Concluiu-se que a orientação verbal deve ser tentada sempre (indice de sucesso de $59,4 \%$ ) como a primeira escolha terapêutica para mulheres com mastalgia cíclica.

Palavras-chaves: Mama: doenças benígnas. Mastalgia.

\section{Estudo de Fatores Relacionados com a Violência Sexual contra Crianças, Adolescentes e} Mulheres Adultas

Autor: Jeferson Drezett Ferreira

Orientador: Prof. Dr. César Eduardo Fernandes

Tese apresentada ao Curso de Pós-Graduação do Centro de Referência da Saúde da Mulher e de Nutrição, Alimentação e Desenvolvimento Infantil; São Paulo; Área de Concentração em Ginecologia, para a obtenção do título de Doutor em Medicina, 19 de abril de 2000.

Entre julho de 1994 e agosto de 1999 foram estudadas, retrospectivamente, 1189 pacientes vítimas de estupro e/ou atentado violento ao pudor atendidas no Centro de Referência da Saúde da Mulher. As pacientes foram alocadas em três grupos de estudo: 71 crianças (idade $<10$ anos); 546 adolescentes (idade $\geq 10$ e $<20$ anos) e 572 adultas (idade $\geq$ que 20 anos). O objetivo foi estudar, comparativamente: tipo de crime sexual; constrangimento imposto; presunção de violência; identificação, tipificação e número de agressores; atividade da vítima no momento do crime; ocorrência e tipificação do trauma genital e extragenital; início de atividade sexual prévia ao crime. Concluímos que o estupro predominou entre adolescentes $(59,2 \%)$ e adultas $(62,1 \%)$ e o atentado violento ao pudor entre crianças $(46,5 \%)$. A grave ameaça foi o principal constrangimento imposto às adolescentes $(63,2 \%)$ e adultas $(67,8 \%)$ e a violência presumida, às crianças $(63,4 \%)$. A violência presumida, devido à deficiência mental, foi expressiva entre adolescentes $(35,1 \%)$ e adultas $(70 \%)$, enquanto que, nas crianças, a inocencia consilli foi fator exclusivo. O uso de substâncias hipnóticas foi mais freqüente nas adultas (20\%). Agressor desconhecido prevaleceu entre adolescentes $(86,6 \%)$ e adultas $(88,1 \%)$. Nas crianças predominaram agressores identificáveis $(84,5 \%)$, principalmente aqueles do núcleo familiar. Nas adultas destacaram-se os parceiros e ex-parceiros $(25,2 \%)$. O vizinho foi agressor mais freqüente entre adolescentes $(27,6 \%)$ e adultas $(27,9 \%)$. O crime sexual ocorreu durante atividades cotidianas em espaços públicos, nas adolescentes $(78,2 \%)$ e adultas $(82,9 \%)$, e dentro de espaços privados nas crianças $(70,5 \%)$. O trauma genital foi mais freqüente entre crianças $(8,2 \%)$, e os extragenitais observados somente em adolescentes $(11 \%)$ e adultas $(14,4 \%)$. A maioria das adultas referiu ter atividade sexual prévia ao crime $(88,5 \%)$, enquanto que $37,1 \%$ das adolescentes ainda não havia iniciado vida sexual.

Palavras-chave: Infância e adolescência. Violência sexual. Trauma genital. 